\title{
Faktor yang Mempengaruhi Nilai Perusahaan Manufaktur yang Terdaftar di BEI
}

\author{
Irvandy dan Ignatius Roni Setyawan \\ Program Studi Manajemen Fakultas Ekonomi dan Bisnis \\ Universitas Tarumanagara \\ Email: vandylee98@gmail.com
}

\begin{abstract}
The purpose of this study is to examine the effect of company growth, company size, and ownership structure on company value on manufacturing companies listed on Indonesia Stock Exchange in the 2016-2019 period. Number of samples are 19 samples by purposive sampling method. Data were collected through Indonesia Stock Exchange official website, which are idx.co.id and idnfinancials.com. Data were processed by using Eviews10 software. The results in this study show that company size has a negative significant effect on company value, while company growth and ownership structure have no significant effect on company value. This research can be studied by managers to determine the factors that influence the value of the company in manufacturing companies listed on the Stock Exchange.
\end{abstract}

\section{Keywords: Company Growth, Company Size, Ownership Structure, Company Value}

\begin{abstract}
Abstrak: Tujuan penelitian ini adalah untuk mengetahui pengaruh pertumbuhan perusahaan, ukuran perusahaan, dan struktur kepemilikan terhadap nilai perusahaan pada perusahaan manufaktur yang terdaftar di BEI periode 2016-2019. Sampel penelitian ini adalah sebanyak 19 sampel yang dipilih melalui metode purposive sampling. Data perusahaan untuk pemilihan sampel diambil dari website resmi Bursa Efek Indonesia, yaitu idx.co.id dan idnfinancials.com. Pengolahan data dilakukan dengan menggunakan software Eviews10. Hasil penelitian ini menunjukkan bahwa ukuran perusahaan memiliki pengaruh negatif signifikan terhadap nilai perusahaan. Sedangkan pertumbuhan perusahaan dan struktur kepemilikan tidak memiliki pengaruh signifikan terhadap nilai perusahaan. Penelitian ini dapat dipelajari oleh manajer untuk mengetahui faktor yang mempengaruhi nilai perusahaan pada perusahaan manufaktur yang terdaftar di BEI.
\end{abstract}

Kata Kunci: pertumbuhan perusahaan, ukuran perusahaan, struktur kepemilikan, nilai perusahaan

\section{LATAR BELAKANG}

Perusahaan yang didirikan akan mungkin memiliki beberapa tujuan seperti mendapat keuntungan, meningkatkan kesejahteraan pemilik perusahaan, memproduksi barang untuk memenuhi kebutuhan konsumen, mempertahankan kelangsungan perusahaan, menyediakan lapangan kerja dan lainnya. Salah satu tujuan perusahaan yaitu meningkatkan kesejahteraan pemilik perusahaan dapat diukur dnegan melihat nilai perusahaan. Nilai perusahaan adalah suatu cerminan atau refleksi kinerja perusahaan selama suatu periode waktu. Nilai perusahaan dapat juga dikaitkan dengan harga saham perusahaan tersebut. kinerja yang baik tentu akan meningkatkan nilai perusahaan dan harga saham perusahaan tersebut.

Nilai perusahaan dipengaruhi oleh berbagai faktor, baik faktor internal maupun faktor external. Pertumbuhan positif tentu diinginkan oleh investor, dan bila saham sedang tinggi permintaannya maka harga saham tentu akan naik juga. Pertumbuhan perusahaan adalah kenaikan atau penurunan total aset yang dimiliki perusahaan. Dengan membandingkan aset 
perusahaan dari tahun ke tahun, maka kita dapat melihat pertumbuhan yang dialami oleh perusahaan.

Selain pertumbuhan perusahaan, ukuran perusahaan juga dapat menjadi faktor yang mempengaruhi nilai perusahaan. Perusahaan yang memiliki ukuran lebih besar relatif dengan pesaingnya dalam suatu pasar akan memiliki kontrol yang lebih baik terhadap kondisi pasar, yang membuat mereka mampu menghadapi persaingan ekonomi dan tidak rentan terhadap fluktuasi ekonomi. Semakin besar penjualan bersih suatu perusahaan, maka semakin besar pula ukuran perusahaannya. semakin besar aset yang dimiliki perusahaan, maka semakin besar juga modal yang tertanam diperusahaan tersebut. hal ini mendukung pernyataan Sujoko dan Soebiantoro (2007) ukuran perusahaan merupakan ukuran atau besarnya aset yang dimiliki oleh perusahaan dan mempunyai pengaruh terhadap nilai perusahaan.

Struktur kepemilikan suatu perusahaan juga dapat mempengaruhi besar kecilnya nilai perusahaan. Shoaib dan Yasushi (2015) membagi ownership structure menjadi internal ownership dan external ownership. Manajer, sebagai wakil pemilik perusahan, memiliki tanggung jawab untuk mengelola perusahaan dengan tujuan meningkatkan nilai perusahaan. Agar manajer bekerja dengan optimal, perusahaan dapat memberikan saham kepada manajer (internal ownership atau kepemilikan manajerial) agar manajer memiliki rasa kepemilikan terhadap perusahaan tersebut. kepemilikan manajerial ini bagai pisau bermata dua, di mana sisi baiknya manajer akan bekerja dengan kinerja tinggi karena memiliki rasa kepemilikan di perusahaan tersebut dan sisi buruk di mana manajer mengambil kebijakan yang hanya bertujuan meningkatkan kesejahteraan mereka sendiri.

Berdasarkan hal-hal yang dijelaskan sebelumnya, penelitian ini dilakukan untuk mengetahui pengaruh pertumbuhan perusahaan, ukuran perusahaan, dan struktur kepemilikan terhadap nilai perusahaan.

\section{KAJIAN TEORI}

Teori Signalling. Ada cukup banyak teori yang berkaitan dengan nilai perusahaan, seperti teori sinyal dan teori keagenan. Sinyal menurut Brigham dan Hauston (2011) adalah suatu aksi atau tindakan yang diambil oleh pihak perusahaan untuk memberikan gambaran atau petunjuk bagi investor-investor tentang bagaimana pihak agen (manajemen) perusahaan melihat prospek dari perusahaan. Sinyal ini dapat berupa informasi tentang apa saja yang dilakukan oleh pihak manajemen untuk mewujudkan keinginan dari pemilik perusahaan. Informasi yang dipublikasikan oleh pihak perusahaan sangatlah penting karena informasi tersebut memiliki pengaruh terhadap keputusan untuk berinvestasi para pihak eksternal. Informasi tersebut dapat dipakai sebagai penentu apakah saham perusahaan tersebut layak dibeli atau tidak oleh investor.

Teori sinyal ini menunjukan bahwa adanya suatu asimetri informasi yang timbul dari antara pihak agen (manajemen) perusahaan dengan pihak prinsipal (pemilik) perusahaan atau pihak yang memiliki kepentingan dengan informasi yang dibicarakan tersebut. teori ini berpendapat bahwa seharusnya perusahaan dapat dan harus memberikan sinyal-sinyal kepada pengguna laporan keuangan seperti investor atau pengamat, ahli keuangan. Sinyal ini dapat berupa informasi mengenai tindakan apa yang sudah dilakukan manajemen untuk melakukan apa yang diinginkan pemilik. Secara singkat, teori ini menjelaskan bahwa pemberian sinyal (informasi) dapat dilakukan pihak manajemen untuk meminimalisir adanya asimetri informasi.

Teori Keagenan. Teori keagenan adalah suatu kontrak di bawah satu atau lebih yang melibatkan agen untuk melaksanakan beberapa layanan bagi mereka dengan melakukan pendelegasian wewnang pengambilan keputusan kepada agen (Jensen dan Meckling, 1976). 
Teori ini menyatakan tentang hubungan kerja yang dimiliki antara pemilik perusahaan (shareholder) dengan agen (manajemen); kontrak di mana satu atau lebih orang (prinsipal) memerintah orang lain (agen) untuk melakukan jasa atas nama prinsipal serta memberi wewenang kepada agen untuk membuat keputusan terbaik bagi prinsipal (Ichsan, 2013). Jika prinsipal dan agen memiliki tujuan yang sama, maka agen akan mendukung dan melaksanakan semua yang diperintahkan oleh prinsipal.

Permasalah timbul saat agen tidak menjalankan perintah prinsipal untuk kepentingannya sendiri seperti contoh ini, pemerintah adalah prinsipal sedangkan perusahaan swasta adalah agen. Pemerintah memerintahkan kepada perusahaan swasta untuk membayar pajak sesuai dengan peraturan perundang-undangan yang berlaku. Namun kenyataannya yang terjadi adalah perusahaan lebih mengutamakan kepentingan atau tujuannya yaitu memaksimalkan kekayaan pemilik perusahaan tersebut dengan cara meminimalisir beban, termasuk beban pajak. Manajer perusahaan mengambil keputusan sebagai agen dengan mengeluarkan kebijakan-kebijakan yang akan memaksimalkan laba yang dihasilkan.

Teori agensi ini berfungsi untuk menganalisa dan menemukan solusi terhadap masalah yang ada dalam hubungan keagenan antara prinsipal dan agen. Dalam hubungan antara prinsipal dan agen, prinsipal harus mengawasi agen agar tidak melakukan tindakan yang dapat merugikan pihak prinsipal. Pada teori keagenan, setiap pihak diasumsikan selalu bertindak memprioritaskan kepentingan diri sendiri terutama manajemen. Perbedaan posisi, fungsi, kondisi, situasi, tujuan, latar belakang, dan keinginan antara prinsipal dan manajemen akan memunculkan konflik kepentingan sehingga muncullah masalah keagenan.

Pengaruh Pertumbuhan Perusahaan terhadap Nilai Perusahaan. Perusahaan dengan pertumbuhan yang cepat akan mendapatkan result yang positif bagi perusahaan dalam pemantapan kedudukan dalam pasar atau persaingan, menikmati penjualan yang meninggi dan diiringi peninggian pangsa pasar juga. Hermuningsih (2013) menyatakan pertumbuhan perusahaan akan memberikan pengaruh positif kepada nilai perusahaan secara signifikan, dengan kata lain nilai perusahaan akan meningkat apa bila perusahaan memiliki pola pertumbuhan yang cepat. Hestinoviana et al. (2013) dan Wardjono (2010) mengungkapkan hal yang sebaliknya di mana pertumbuhan perusahaan berpengaruh terhadap nilai perusahaan secara signifikan negatif.

H1: Pertumbuhan perusahaan berpengaruh terhadap nilai perusahaan

Pengaruh Ukuran Perusahaan terhadap Nilai Perusahaan. Ukuran perusahaan merupakan salah satu faktor atau variabel yang digunakan untuk mengukur nilai dari suatu perusahaan. Seperti yang sudah diuraikan sebelumnya, ukuran perusahaan adalah suatu penilaian perusahaan yang didasarkan dengan aktiva perusahaan dalam suatu kurun waktu atau periode. Tidak hanya aktiva atau aset, penjualan perusahaan juga dapat digunakan untuk mengukur suatu ukuran perusahaan. Menurut Gill dan Obradovich (2012) ukuran perusahaan memiliki pengaruh positif dan signifikan terhadap nilai perusahaan. Namun menurut Naceur dan Goaied (2002) ukuran perusahaan memiliki pengaruh negatif dan signifikan terhadap nilai perusahaan.

H2: Ukuran perusahaan berpengaruh terhadap nilai perusahaan

Pengaruh Struktur Kepemilikan terhadap Nilai Perusahaan. Perusahaan memiliki tujuan untuk memaksimalkan nilai perusahaan itu sendiri. Nilai perusahaan yang tinggi akan menggambarkan tingginya kesejahteraan pemilik perusahaannya juga. Kesejahteraan pemilik perusahaan dikatakan meningkat karena meningkatnya nilai perusahaan akan ditandai dengan meningkatnya juga harga saham perusahaan. Agency cost dapat diminimalisir dengan cara meningkatkan kepemilikan saham pihak manajemen perusahaan tersebut, dengan demikian 
maka pihak manajemen akan merasakan juga efek dari keputusan yang diambil. Kepemilikan manajerial ini juga diharapkan untuk meningkatkan kemampuan kinerja pihak manajemen perusahaan untuk lebih lagi meningkatkan nilai perusahaan.

H3: Struktur kepemilikan berpengaruh terhadap nilai perusahaan

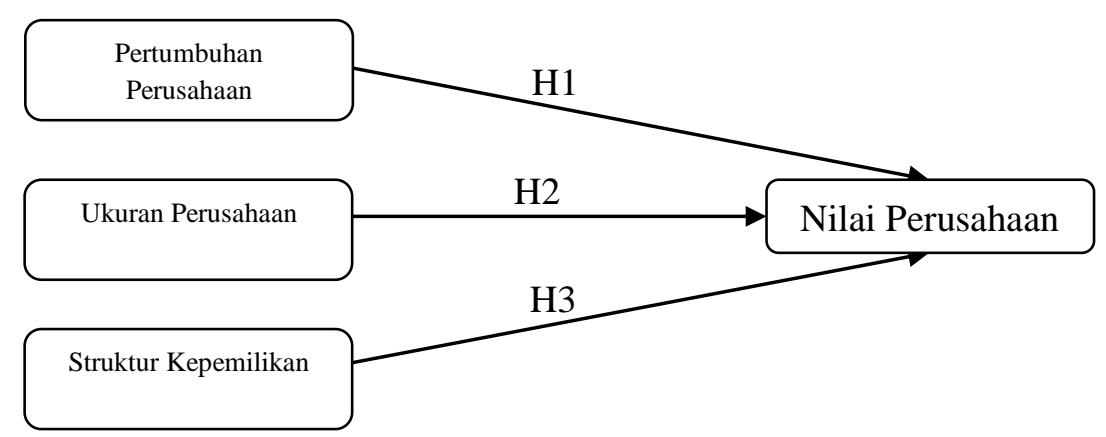

Gambar 1. Kerangka Pemikiran

Berdasarkan kerangka pemikiran di atas, maka dapat dirumuskan hipotesis penilitan sebagai berikut:

H1: Pertumbuhan perusahaan berpengaruh terhadap nilai perusahaan

H2: Ukuran perusahaan berpengaruh terhadap nilai perusahaan

H3: Struktur kepemilikan berpengaruh terhadap nilai perusahaan

\section{METODOLOGI}

Penelitian ini adalah penelitian konklusif dengan desain penelitian kausal yang bertujuan untuk membuktikan hubungan antara variabel terikat dan variabel bebas (Aritonang R., 2007). Penelitian ini menggunakan data sekunder yang diperoleh dari annual report/laporan tahunan perusahaan manufaktur pada periode 2016-2019 dari sumber database Bursa Efek Indonesia yang dapat diunggah di https://www.idx.co.id/. Populasi yang diteliti dalam penelitian ini adalah perusahaan manufaktur yang terdaftar di Bursa Efek Indonesia (BEI). Teknik pengambilan sampel purposive sampling dilakukan dan 19 perusahaan manufaktur yang sesuai dengan kriteria didapatkan.

Variabel dependen pada penelitian ini adalah nilai perusahaan. Nilai perusahaan diukur dengan menggunakan rasio Price to Book Value (PBV)

Rumus perhitungannya:

$$
\boldsymbol{P B} \boldsymbol{V}=\frac{\text { harga per lembar saham }}{\text { nilai buku per lembar saham }}
$$

Pertumbuhan perusahaan diukur dengan mengurangi jumlah aset tahun periode yang diteliti dengan jumlah aset tahun sebelumnya dibagi dengan jumlah aset tahun sebelumnya

Rumus perhitungannya:

$$
\text { Growth }=\frac{\text { ASET } T A H U N_{T}-\text { ASET TAHUN }}{T-1}
$$

Ukuran perusahaan diukur dengan menghitung logaritma natural dari jumlah aset yang dimiliki perusahaan

Rumus perhitungannya:

$$
\text { Size }=\text { Ln Total Assets }
$$


Struktur kepemilikan dengan membagi jumlah saham yang dimiliki manajemen dengan jumlah saham yang beredar lalu dikali $100 \%$

Rumus perhitungannya:

$$
\text { MAN }=\frac{\text { jumlah saham yang dimiliki manajemen }}{\text { jumlah sahamyang beredar }} \times 100 \%
$$

Metode analisis data yang digunakan dalam penelitian ini adalah regresi berganda. Data dianalisis menggunakan program software Eviews10. Model regresi berganda penelitian ini adalah sebagai berikut:

$$
\mathrm{Y}=\alpha+\beta_{1} X_{1}+\beta_{2} X_{2}+\beta_{3} X_{3}+e
$$

(Ghozali \& Ratmono 2017, 53)

Keterangan:

$\begin{array}{ll}\mathrm{Y} & : \text { Nilai Perusahaan } \\ \alpha & : \text { Konstanta / Intersep } \\ \beta_{1}, \beta_{2}, \beta_{3}, & : \text { Koefisien regresi tiap variabel independen } \\ \mathrm{X}_{1} & : \text { Pertumbuhan Perusahaan } \\ \mathrm{X}_{2} & : \text { Ukuran Perusahaan } \\ \mathrm{X}_{3} & : \text { Struktur Kepemilikan } \\ e & : \text { Error term, variabel lain di luar penelitian }\end{array}$

\section{HASIL ANALISIS DATA}

\section{Analisis Statistik Deskriptif}

Tabel 1. Uji Statistik Deskriptif

\begin{tabular}{|c|c|c|c|c|}
\hline & $\begin{array}{c}\text { Nilai } \\
\text { Perusahaan }\end{array}$ & $\begin{array}{c}\text { Pertumbuhan } \\
\text { Perusahaan }\end{array}$ & $\begin{array}{c}\text { Ukuran } \\
\text { Perusahaan }\end{array}$ & $\begin{array}{c}\text { Struktur } \\
\text { Kepemilikan }\end{array}$ \\
\hline Mean & 1.572807 & 0.044743 & 28.26000 & 0.106653 \\
\hline Median & 0.901842 & 0.043920 & 27.92436 & 0.048190 \\
\hline Maximum & 6.857417 & 0.217109 & 32.20096 & 0.380094 \\
\hline Minimum & 0.257034 & -0.169922 & 25.66354 & 0.000157 \\
\hline Std. Dev. & 1.488240 & 0.076225 & 1.897863 & 0.125586 \\
\hline Skewness & 1.608608 & -0.065874 & 0.549326 & 0.887949 \\
\hline Kurtosis & 5.180441 & 3.165311 & 2.461024 & 2.479035 \\
\hline & & & & \\
\hline Jarque-Bera & 47.83189 & 0.141503 & 4.742185 & 10.84653 \\
\hline Probability & 0.000000 & 0.931693 & 0.093379 & 0.004413 \\
\hline & & & & \\
\hline Sum & 119.5334 & 3.400435 & 2147.760 & 8.105639 \\
\hline Sum Sq. Dev. & 166.1144 & 0.435771 & 270.1412 & 1.182890 \\
\hline & & & & 76 \\
\hline Observations & 76 & 76 & 76 & \\
\hline
\end{tabular}

Sumber: hasil pengolahan data menggunakan Eviews 10 
Berikut penjelasan dari hasil statistik deskriptif di atas:

Variabel nilai perusahaan memiliki nilai rata-rata (mean) sebesar 1.572807 , nilai tengah (median) sebesar 0.901842, nilai maksimum sebesar 6.857417, nilai minimum sebesar 0.257034 , standar deviasi sebesar 1.488240, tingkat kesimetrisan kurva adalah menceng positif (mean>median) dengan tingkat kemencengan sebesar 1.608608, dan tingkat keruncingan kurva adalah leptokurtosis dengan nilai sebesar 5.180441.

Variabel pertumbuhan perusahaan memiliki nilai rata-rata (mean) sebesar 0.044743 , nilai tengah (median) sebesar 0.043920, nilai maksimum sebesar 0.217109, nilai minimum sebesar -0.169922 , standar deviasi sebesar 0.076225, tingkat kesimetrisan kurva adalah menceng negatif (mean<median) dengan tingkat kemencengan sebesar -0.065874 , dan tingkat keruncingan kurva adalah leptokurtosis dengan nilai sebesar 3.165311.

Variabel ukuran perusahaan memiliki nilai rata-rata (mean) sebesar 28.26000, nilai tengah (median) sebesar 27.92436, nilai maksimum sebesar 32.20096, nilai minimum sebesar 25.66354, standar deviasi sebesar 1.897863, tingkat kesimetrisan kurva adalah menceng positif (mean>median) dengan tingkat kemencengan sebesar 0.549326, dan tingkat keruncingan kurva adalah platykurtosis dengan nilai sebesar 2.461024.

Variabel struktur kepemilikan memiliki nilai rata-rata (mean) sebesar 0.106653, nilai tengah (median) sebesar 0.048190, nilai maksimum sebesar 0.380094, nilai minimum sebesar 0.000157, standar deviasi sebesar 0.125586, tingkat kesimetrisan kurva adalah menceng positif (mean>median) dengan tingkat kemencengan sebesar 0.887949, dan tingkat keruncingan kurva adalah platykurtosis dengan nilai sebesar 2.479035 .

\section{Uji t}

Tabel 2. Uji t

\begin{tabular}{|c|c|c|c|c|}
\hline Variable & Coefficient & Std. Error & t-Statistic & Prob. \\
\hline C & 31.74543 & 13.21746 & 2.401781 & 0.0198 \\
\hline $\begin{array}{c}\text { Pertumbuhan } \\
\text { Perusahaan }\end{array}$ & 1.189952 & 0.729171 & 1.631924 & 0.1085 \\
\hline $\begin{array}{c}\text { Ukuran } \\
\text { Perusahaan }\end{array}$ & -1.049534 & 0.464130 & -2.261291 & 0.0278 \\
\hline $\begin{array}{c}\text { Struktur } \\
\text { Kepemilikan }\end{array}$ & -5.307423 & 3.384515 & -1.568149 & 0.1227 \\
\hline
\end{tabular}

Sumber: hasil pengolahan data menggunakan Eviews 10

Berdasarkan hasil uji t di atas, variabel ukuran perusahaan menunjukan nilai probabilitas lebih kecil dari $\alpha(0.05)$ dan nilai t-Statistic lebih besar dari hasil t tabel sebesar 1.99167 sehingga dapat disimpulkan variabel ukuran perusahaan berpengaruh terhadap nilai perusahaan. Sedangkan variabel pertumbuhan perusahaan dan struktur kepemilikan menunjukan nilai probabilitas lebih besar dari $\alpha(0.05)$ dan nilai t-Statistic lebih kecil dari hasil t tabel sebesar 1.99167 sehingga dapat disimpulkan variabel pertumbuhan perusahaan dan struktur kepemilikan tidak berpengaruh terhadap nilai perusahaan.

\section{Analisis Regresi Linear Berganda}

Nilai Perusahaan $=31.74543+1.189952($ Pertumbuhan Perusahaan $)-1.049534$

(Ukuran Perusahaan) - 5.307423 (Struktur Kepemilikan) $+e$ 
Goodness of Fit

Tabel 3. Uji Goodness of Fit

\begin{tabular}{|c|c|}
\hline F-Statistic & 47.13112 \\
\hline Prob (F-Statistic) & 0.000000 \\
\hline
\end{tabular}

Sumber: hasil pengolahan data menggunakan Eviews 10

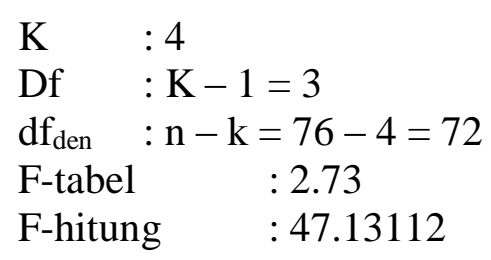

Berdasarkan hasil uji goodness of fit di atas, diketahui F-Statistic memiliki nilai 47.13112 lebih besar dari F-tabel 2.73. Selain itu, nilai probabilitas menunjukan bahwa nilai probabilitas lebih kecil dari $\alpha(0.05)$ yaitu sebesar 0,000000 . Sehingga dapat disimpulkan variabel independen secara simultan berpengaruh signifikan terhadap variabel dependen dan model fit untuk digunakan dalam penelitian.

\section{DISKUSI}

Pengujian hipotesis pertama (H1) tidaklah sejalan dengan hasil penelitian yang diperoleh I Nyoman Agus Suwardika \& I Ketut Mustanda (2017) yang menyatakan bahwa semakin cepat pertumbuhan perusahaan akan mengakibatkan penurunan pada nilai perusahaan. Hal ini dapat terjadi karena semakin cepat pertumbuhan perusahaan maka semakin besar pula dana yang harus tersedia untuk kegiatan investasi perusahaan, baik sumber dana dari dalam maupun luar perusahaan.

Pengujian hipotesis kedua (H2) tidaklah sejalan dengan hasil penelitian yang diperoleh Husna \& Satria (2019) yang menyatakan bahwa ukuran perusahaan memiliki dampak terhadap nilai perusahaan. Semakin besar aset yang dimiliki, maka semakin besar pula modal yang dimiliki. Hal tersebut tentu akan meningkatkan rasio PBV. Ukuran perusahaan dapat dijadikan patokan bahwa perusahaan tersebut memiliki kinerja yang baik sehingga ukuran perusahaan memiliki efek positif terhadap nilai perusahaan

Pengujian hipotesis ketiga (H3) sejalan dengan hasil penelitian yang didapat oleh Wardani dan Hermuningsih (2011) yang menyatakan bahwa insider ownership di Indonesia tidak mampu untuk mengendalikan nilai perusahaan dan struktur kepemilikan tidak memiliki hubungan dengan nilai perusahaan.

\section{KESIMPULAN}

Ada beberapa saran yang dapat peneliti berikan untuk membantu dalam perihal keterbatasan dari penelitian ini:

1. Penelitian selanjutnya dapat memperpanjang periode penelitian agar mendapat hasil yang lebih optimal dan akurat.

2. Memisahkan pengolahan data setiap sektor agar hasil pengolahan data lebih akurat.

3. Menambahkan variabel independen untuk diteliti yang mungkin dapat mempengaruhi nilai perusahaan. 


\section{DAFTAR PUSTAKA}

Aritonang, R. L. (2007). Riset Pemasaran: Teori dan Praktik (1 ed). Bogor: Ghalia Indonesia.

Brigham, E. F. (2011). Dasar-dasar Manajemen Keuangan Terjemahan. Edisi 10. Jakarta: Salemba Empat.

Ghozali, I. d. (2017). Analisis Multivariat dan Ekonometrika dengan Eviews 10. Semarang: Badan Penerbit Universitas Diponegoro.

Gill, A. d. (2012). The Impact of Corporate Governance and Financial Leverage on the Value of American Firms. International Research Journal of Finance and Economics (Issue 91), 1-14.

Hermuningsih, S. (2013, Oktober). Pengaruh Profitabilitas, Growth Opportunity, Struktur Modal Terhadap Nilai Perusahaan Pada Perusahaan Publik di Indonesia. Buletin Ekonomi Moneter dan Perbankan.

Hestinoviana, V. S. (2013). The Influence of Profitability, Solvability, Asset Growth, and Sales Growth Toward Firm Value (Empirical Study on Mining Comapnies Which Listed on Indonesia Stock Exchange). Jurnal Administrasi Bisnis. Vol. 4, No. 1.

Husna, A. d. (2019). Effects of Return on Asset, Debt to Asset Ratio, Current Ratio, Firm Size, and Dividend Payout Ratio on Firm Value. International Journal of Economics and Financial Issues, 50-54.

Ichsan, R. (2013). Teori Keagenan. Retrieved from https://bungrandhy.wordpress.com/2013/01/12/teori-keagenan-agency-theory/.

Meckling, J. M. (1976). Theory of the firm: Managerial behaviour, agency cost and ownership structure. Journal of Finance Economic, Vol. 3, 305-360.

Naceur, S. b. (2002). The relationship between dividend policy, financial structure, profitability and firm value. Applied Financial Economic. 12, 843-849.

Shoaib, K. d. (2015). Capital Structure and Managerial Ownership: Evidence from Pakistan. Business and Economic Horizons (BEH). Vol.11, 131-142.

Soebiantoro, S. d. (2007). Pengaruh Struktur Kepemilikan Saham, Leverage, Faktor Interen, dan Faktor Eksteren terhadap Nilai Perusahaan. Jurnal Manajemen dan Kewirausahaan. Vol. 9, No. 1, 41-48.

Suwardika, I. N. (2017). PENGARUH LEVERAGE, UKURAN PERUSAHAAN, PERTUMBUHAN pERUSAHAAN, DAN PROFITABILITAS TERHADAP NILAI PERUSAHAAN PADA PERUSAHAAN PROPERTI. E-Jurnal Manajemen Unud, Vol. 6 No. 3, 1248-1277.

Wardani, D. K. (2011). PENGARUH STRUKTUR KEPEMILIKAN TERHADAP NILAI PERUSAHAAN DENGAN KINERJA KEUANGAN DAN KEBIJAKAN HUTANG SEBAGAI VARIABEL INTERVENING . Jurnal Siasat Bisnis, Vol. 15 No. 1, 27-36.

Wardjono. (Mei 2010). Analisis Faktor-faktor yang Mempengaruhi Price to Book Value dan Implikasinya pada Return Saham. Dinamika Keuangan dan Perbankan, Vol. 2, No.1, 83-96. 